\title{
Cyclic helix B peptide protects HK-2 cells from oxidative stress by inhibiting ER stress and activating Nrf2 signalling and autophagy
}

\author{
LONG LI $^{*}$, MIAO LIN ${ }^{2 *}$, LEXI ZHANG ${ }^{3 *}$, SHANG HUANG $^{4}, \mathrm{CHAO} \mathrm{HU}^{1}$, LONG ZHENG ${ }^{1}$, \\ LIPING LI $^{1}$, CHAO ZHANG ${ }^{1}$, CHENG YANG ${ }^{1}$, YAQIU LONG ${ }^{5}$, RUIMING RONG ${ }^{1}$ and TONGYU ZHU ${ }^{1}$ \\ Departments of ${ }^{1}$ Urology and ${ }^{2}$ Thoracic Surgery, Zhongshan Hospital, Fudan University, Shanghai 200032; ${ }^{3}$ Department \\ of Urology, Anhui Provincial Hospital, Hefei, Anhui 230001; ${ }^{4}$ Department of Urology, Guangdong General Hospital, \\ Guangdong Academy of Medical Sciences, Guangzhou, Guangdong 510080; ${ }^{5}$ CAS Key Laboratory of Receptor \\ Research, Shanghai Institute of Materia Medica, Chinese Academy of Sciences, Shanghai 201203, P.R. China
}

Received March 31, 2016; Accepted March 7, 2017

DOI: $10.3892 / \mathrm{mmr} .2017 .7588$

\begin{abstract}
Renal ischemia-reperfusion injury (IRI) is present in numerous diseases and is observed following certain treatments, including renal transplantation. Preventing tubular epithelial cells (TECs) from undergoing apoptosis is vital for treatment of renal IRI. Cyclic helix B peptide (CHBP) is a novel agent that has a protective effect on renal IRI in vivo. In the present study, the effect and underlying mechanism of CHBP on TECs was investigated. The HK-2 human renal proximal tubular epithelial cell line was treated with $500 \mu \mathrm{mol} / 1 \mathrm{H}_{2} \mathrm{O}_{2}$ for $4 \mathrm{~h}$ prior to determining the effect of CHBP pretreatment for $1 \mathrm{~h}$ on cell viability, caspase 3 activity and expression levels, expression levels of oxidative stress markers, endoplasmic reticulum (ER) stress markers, NF-E2-related factor 2 (Nrf2), heme oxygenase-1 (HO-1) and autophagy markers. This was investigated using a Cell Counting kit 8 , a terminal deoxynucleotidyl transferase-mediated dUTP nick-end labelling assay, western blotting, reverse transcription-quantitative polymerase chain reaction and immunocytochemistry. Results revealed that pretreatment with CHBP enhanced HK-2 cell viability, the glutathione/glutathione disulphide ratio, activation of Nrf2 and mRNA expression levels of HO-1 and the expression levels of beclin-1 and light chain 3 A/B-II/I. Conversely, CHBP pretreatment reduced the expression levels of reactive oxygen species, the activity and protein expression levels of capase-3, the mRNA and protein expression levels
\end{abstract}

Correspondence to: Professor Tongyu Zhu or Professor Ruiming Rong, Department of Urology, Zhongshan Hospital, Fudan University, 180 Fenglin Road, Shanghai 200032, P.R. China

E-mail: zs_tyzhu@163.com

E-mail: rong.ruiming@zs-hospital.sh.cn

*Contributed equally

Key words: cyclic helix B peptide, renal ischemia-reperfusion injury, tubular epithelial cells, oxidative stress, endoplasmic reticulum stress, autophagy of $\mathrm{C} / \mathrm{EBP}$ homologous protein and binding immunoglobulin protein, and the expression levels of phosphorylated (p)-mechanistic target of rapamycin (mTOR) Ser2448 and p62 during oxidative stress. However, the expression of p-mTOR Ser2481 was enhanced after CHBP pretreatment. CHBP pretreatment reduced the expression levels of reactive oxygen species, the activity and protein expression levels of capase-3, the mRNA and protein expression levels of $\mathrm{C} / \mathrm{EBP}$ homologous protein and binding immunoglobulin protein, and the expression levels of phosphorylated (p)-mechanistic target of rapamycin (mTOR) Ser2481, p62 and p-mTOR Ser 2448 during oxidative stress. In conclusion, CHBP pretreatment protected HK-2 cells from $\mathrm{H}_{2} \mathrm{O}_{2}$-induced injury, inhibited ER stress and pro-apoptotic pathways, and activated the Nrf2 signalling pathway and autophagy. These results provide a potential mechanism of how CHBP protects against renal IRI.

\section{Introduction}

Renal ischemia-reperfusion injury (IRI) is characterized by tubular epithelial cell (TEC) injury and is present in numerous diseases and following certain treatments, including shock, renal transplantation and cardiac surgery (1). The underlying mechanism of IRI includes immune injury, mitochondrial dysfunction, endoplasmic reticulum (ER) stress and caspase cascade disorders (2). Preventing TECs from undergoing apoptosis is vital for treatment of renal IRI.

During IRI, oxidative stress disturbs redox balance and results in aberrations in various signalling pathways. ER stress serves a role in the progression of renal IRI (3). Oxidative stress leads to ER stress with the accumulation of misfolded and unfolded proteins in the ER lumen (4). ER stress is initiated by alterations in heterologous protein-protein interactions, including the dissociation of the chaperone binding immunoglobulin protein (BiP). The unfolded protein response (UPR) is induced under moderate and transient ER stress. Activation of the UPR results in reduced ER burden and the restoration of ER equilibrium (5). NF-E2-related factor 2 (Nrf2) is a master transcriptional regulator of antioxidant proteins, including heme oxygenase-1 (HO-1). The Nrf2 signalling pathway is activated during adaptive UPR, and protects TECs 
from oxidative stress-induced injury (6). However, during IRI, intensive ER stress is initiated by $\mathrm{C} / \mathrm{EBP}$ homologous protein (CHOP) accumulation, inositol-requiring enzyme 1 (IRE1) phosphorylation and c-Jun N-terminal kinase (JNK) activation, leading to the apoptotic UPR phase.

Helix B surface peptide (HBSP), a linear peptide derived from non-erythropoietic helix B of erythropoietin, has been demonstrated to be a protective agent against ischemic injury $(7,8)$. In addition, it does not interact with erythropoietic receptors, or promote erythropoiesis and blood viscosity $(7,8)$. This suggests that HBSP is a better candidate for renal protection than erythropoietin. However, the plasma half-life of HBSP is only $2 \mathrm{~min}$, which significantly restricts its application in vivo (8). To address this problem, thioether-cyclized helix B peptide (CHBP) was synthesized by employing a cyclization strategy to improve its metabolic stability (9). The present study demonstrated that $\mathrm{CHBP}$ has significant metabolic stability and may attenuate kidney injury by reducing inflammation and apoptosis (9). In the present study, the effect of CHBP and the underlying mechanism in the HK-2 human renal proximal tubular cell line was investigated, under oxidative stress induced by $\mathrm{H}_{2} \mathrm{O}_{2}$, to further understand the protective role of CHBP in renal IRI.

\section{Materials and methods}

Materials and reagents. The HK-2 human renal proximal tubular cell line was provided by Dr Honghong Chen (Institute of Radiation Medicine, Fudan University, Shanghai, China). Dulbecco's modified Eagle's medium (DMEM) F12 and foetal bovine serum (FBS) were purchased from Gibco; Thermo Fisher Scientific, Inc. (Waltham, MA, USA). CHBP was synthesized as previously described (9). The Cell Counting kit 8 (CCK-8), glutathione/glutathione disulphide (GSH/GSSG) assay kit, reactive oxygen species (ROS) assay kit, nuclear and cytoplasmic protein extraction kit, Annexin $\mathrm{V}$ apoptosis detection kit and one-step terminal deoxynucleotidyl transferase-mediated dUTP nick-end label (TUNEL) apoptosis assay kit were purchased from Beyotime Institute of Biotechnology (Haimen, China). DNA oligonucleotides were synthesized by Shanghai BoShang Biotechnology Co., Ltd. (Shanghai, China). Antibodies against cleaved caspase-3 (cat. no. 9661; 1:1,000), BiP (cat. no. 3177; 1:1,000), CHOP (cat. no. 5554; 1:1,000), HO-1 (cat. no. 5853; 1:1,000), beclin-1 (cat. no. 3495 ; 1:1,000), light chain 3 (LC3) A/B (cat. no. 12741; 1:1,000), phosphorylated (p)-mechanistic target of rapamycin (mTOR) Ser2481 (cat. no. 2974; 1:1,000), p-mTOR Ser2448 (cat. no. 5536; 1:1,000), p62 (cat. no. 5114; 1:1,000), mTOR (cat. no. $2972 ; 1: 1,000$ ), and $\beta$-actin (cat. no. 3700; 1:1,000) were purchased from Cell Signaling Technology, Inc. (Danvers, MA, USA). Antibodies against Nrf2 (rabbit anti-human monoclonal; cat. no. sc-722; 1:200) and lamin B (goat anti-human monoclonal; cat. no. sc-6216; 1:200) were purchased from Santa Cruz Biotechnology, Inc. (Dallas, TX, USA). The secondary antibody (cat. no. P0186; 1:1,000) used in the immunocytochemistry assay (Goat anti-Rabbit) were purchased from Beyotime Institute of Biotechnology (Haimen, China).

Cell culture and $\mathrm{H}_{2} \mathrm{O}_{2}$ treatment. $\mathrm{HK}-2$ cells were cultured in DMEM F12 medium supplemented with $10 \% \mathrm{FBS}$ at $37^{\circ} \mathrm{C}$ and
$5 \% \mathrm{CO}_{2}$ for $24 \mathrm{~h}$. Confluent monolayers $(80 \%)$ were cultures in 6-well plates and pretreated with or without $20 \mathrm{nmol} / \mathrm{l} \mathrm{CHBP}$ for $1 \mathrm{~h}$ prior to treatment with $500 \mu \mathrm{mol} / 1 \mathrm{H}_{2} \mathrm{O}_{2}$ diluted in serum-free media, for $4 \mathrm{~h}$.

Cell viability analysis. Cell proliferation and viability were measured using a CCK-8 assay kit. Briefly, HK-2 cells were seeded in 96-well tissue culture plates for $24 \mathrm{~h}(8,000 /$ well $)$. Subsequently, cells were pretreated with or without 10,20 and $40 \mathrm{nmol} / \mathrm{l} \mathrm{CHBP}$ for $1 \mathrm{~h}$ prior treatment with $500 \mu \mathrm{mol} / 1 \mathrm{H}_{2} \mathrm{O}_{2}$ diluted in serum-free media for $4 \mathrm{~h}$. Control cells were treated with media alone. Subsequently, cells were pretreated with or without 10, 20 and $40 \mathrm{nmol} / \mathrm{l} \mathrm{CHBP}$ for $1 \mathrm{~h}$ prior to treatment with $500 \mu \mathrm{mol} / 1 \mathrm{H}_{2} \mathrm{O}_{2}$ diluted in serum-free media, for $4 \mathrm{~h}$. Cells were washed twice with PBS and incubated with culture medium containing $10 \% \mathrm{CCK}-8$ solution at $37^{\circ} \mathrm{C}$ for $1 \mathrm{~h}$. The absorbance of the wells was detected using a microplate reader at a wavelength of $450 \mathrm{~nm}$, generating an optical density (OD) value. Culture medium containing $10 \%$ CCK-8 solution was utilized as a negative control.

Measurement of oxidative stress. ROS activity levels were determined using a dichloro-dihydro-fluorescein diacetate assay kit. The GSH/GSSG ratio was measured using a GSH/GSSG assay kit. HK-2 cells were washed twice with PBS and suspended in ice-cold 5\% metaphosphoric acid. Cells were homogenized with a TissueLyser LT (Qiagen $\mathrm{GmbH}$, Hilden, Germany), and suspensions were transferred to a microtube and centrifuged at $10,000 \mathrm{x} \mathrm{g}$ for $10 \mathrm{~min}$ at $4^{\circ} \mathrm{C}$. The collected supernatant was utilized to analyse GSH and GSSG concentrations in addition to ROS levels, according to the manufacturer's protocol.

Western blot analysis. HK-2 cells were washed twice in PBS and harvested. Extra-nuclear and intra-nuclear proteins were isolated using a protein extraction kit (Beyotime Institute of Biotechnology), according to the manufacturer's protocol. Western blotting was performed according to a previously published procedure (10). Expression levels of cleaved caspase-3, BiP, CHOP, Nrf2, HO-1, Beclin-1, LC3 A/B, p-mTOR Ser2448, p-mTOR Ser2481, p62 and mTOR were quantified using Image-Pro plus software version 6.0 (Media Cybernetics, Inc., Rockville, MD, USA). Extra-nuclear proteins were normalized to $\beta$-actin and intra-nuclear proteins were normalized to lamin $\mathrm{B}$.

TUNEL assay. Apoptosis of HK-2 cells was determined using a one-step TUNEL assay kit according to the manufacturer's protocol. Briefly, cells were washed with PBS and fixed in 4\% paraformaldehyde for $30 \mathrm{~min}$. Cells were washed with PBS and incubated with cold PBS containing $0.1 \%$ Triton X-100 for 2 min in a light-proof container. Cells were washed with PBS and incubated with TUNEL reaction buffer for $1 \mathrm{~h}$ at $37^{\circ} \mathrm{C}$ in a humidified light-proof chamber. Following a final wash with PBS, cells were visualized using a laser scanning confocal microscope (Leica Microsystems, Inc., Wetzlar, Germany) at a wavelength of $530 / 485 \mathrm{~nm}$. 
using TRIzol reagent (Invitrogen; Thermo Fisher Scientific, Inc.) according to the manufacturer's protocol. cDNA was synthesized from 3-5 $\mu \mathrm{g}$ total RNA in a $20 \mu \mathrm{l}$ reaction mixture using a RevertAid First Strand cDNA Synthesis kit (Thermo Fisher Scientific, Inc.). The specific primers for the genes that encode human BiP, CHOP and $\beta$-actin are listed in Table I. RT-qPCR was performed using ABsolute qPCR SYBR Green mix (Thermo Fisher Scientific, Inc.) on an Eppendorf Mastercycler ${ }^{\circledR}$ ep realplex system as follows: Incubation for $2 \mathrm{~min}$ at $50^{\circ} \mathrm{C}$ and $10 \mathrm{~min}$ at $95^{\circ} \mathrm{C}$. This was followed by a 2-step PCR program of $95^{\circ} \mathrm{C}$ for $15 \mathrm{sec}$ and $60^{\circ} \mathrm{C}$ for $20 \mathrm{sec}$ for 45 cycles. (Eppendorf, Hamburg, Germany). mRNA expression levels were normalized to those of $\beta$-actin in the same samples using the $2^{-\Delta \Delta \mathrm{Cq}}$ method (11).

Immunocytochemistry assay. Experimental HK-2 cells were cultured in 12-well plate $\left(10^{5} /\right.$ well $)$ after $\mathrm{H}_{2} \mathrm{O}_{2}$ stimulation for $4 \mathrm{~h}$ were fixed in $4 \%$ paraformaldehyde for $10 \mathrm{~min}$. Following a wash with PBS for $5 \mathrm{~min}$ at room temperature, cells were permeabilized with Triton X 100 for 5 min followed by PBS for $5 \mathrm{~min}$ and then incubated in blocking solution $5 \% \mathrm{BSA}$ in PBS; Beyotime Institute of Biotechnology) for $1 \mathrm{~h}$ at room temperature. Cells were incubated with primary antibodies against Nrf2 (1:200) and LC3A/B (1:100) for $60 \mathrm{~min}$. Following three rinses with $\mathrm{PBS}$, cells were incubated with a secondary antibody conjugated to fluorescein isothiocyanate for $30 \mathrm{~min}$ at room temperature and washed with PBS. To visualize cell nuclei, slides were counterstained with DAPI (Beyotime Institute of Biotechnology). Samples were examined under a phase contrast microscope equipped with the appropriate fluorescence filters in a total of 10 fields per specimen.

Statistical analysis. Data was analysed using SPSS software version 13.0 (SPSS, Inc., Chicago, IL, USA). The results in two groups were compared using two-tailed independent t-tests, and the results among three or more groups were compared by one-way analysis of variance. Data are expressed as the mean \pm standard deviation. $\mathrm{P}<0.05$ was considered to indicate a statistically significant difference.

\section{Results}

CHBP pretreatment increases $H K-2$ cell viability and reduces oxidative stress levels. The effect of CHBP on viability in HK-2 cells following oxidative stress induced by $\mathrm{H}_{2} \mathrm{O}_{2}$ was determined. Cells were treated with $\mathrm{H}_{2} \mathrm{O}_{2}$ for $1,4,8$ and $16 \mathrm{~h}$ prior to measurement of cell viability via the CCK-8 assay. Results revealed that pretreatment with CHBP significantly reduced the decrease in cell viability caused by $\mathrm{H}_{2} \mathrm{O}_{2}$ alone, and the greatest protection observed at $4 \mathrm{~h}$ (Fig. 1A). Treatment with $\mathrm{H}_{2} \mathrm{O}_{2}$ alone reduced the viability of $\mathrm{HK}-2$ cells by 3 -fold; however, viability of cells treated with $20 \mathrm{nmol} / \mathrm{l}$ CHBP alone was not significantly altered compared with the control (Fig. 1B). Pretreatment with $\mathrm{CHBP}$ resulted in a significant and dose-dependent increase in the viability of $\mathrm{HK}-2$ cells in the presence of $\mathrm{H}_{2} \mathrm{O}_{2}$ compared with cells treated with $\mathrm{H}_{2} \mathrm{O}_{2}$ alone $(\mathrm{P}<0.001$; Fig. 1B). The protective effect of CHBP peaked at $20 \mathrm{nmol} / \mathrm{l}$ (Fig. 1B). In addition, cell viability was greatest following pretreatment with $\mathrm{CHBP}$ for $1 \mathrm{~h}$ prior to $\mathrm{H}_{2} \mathrm{O}_{2}$ exposure for $4 \mathrm{~h}$ (Fig. 1C). To determine
Table I. Primers for quantitative polymerase chain reaction.

\begin{tabular}{ll}
\hline Target & \multicolumn{1}{c}{ Primer $\left(5^{\prime}-3^{\prime}\right)$} \\
\hline BiP & F: AAAGAAGACGGGCAAAGATGT \\
& R: TGCTTGATGCTGAGAAGACAG \\
CHOP & F: ACCACTCTTGACCCTGCTTCT \\
& R: CTCTGGGAGGTGCTTGTGAC \\
$\beta$-actin & F: GTTGTCGACGACGAGCG \\
& R: GCACAGAGCCTCGCCTT
\end{tabular}

F, forward; R, reverse; BiP, binding immunoglobulin protein; $\mathrm{CHOP}$, $\mathrm{C} / \mathrm{EBP}$ homologous protein.
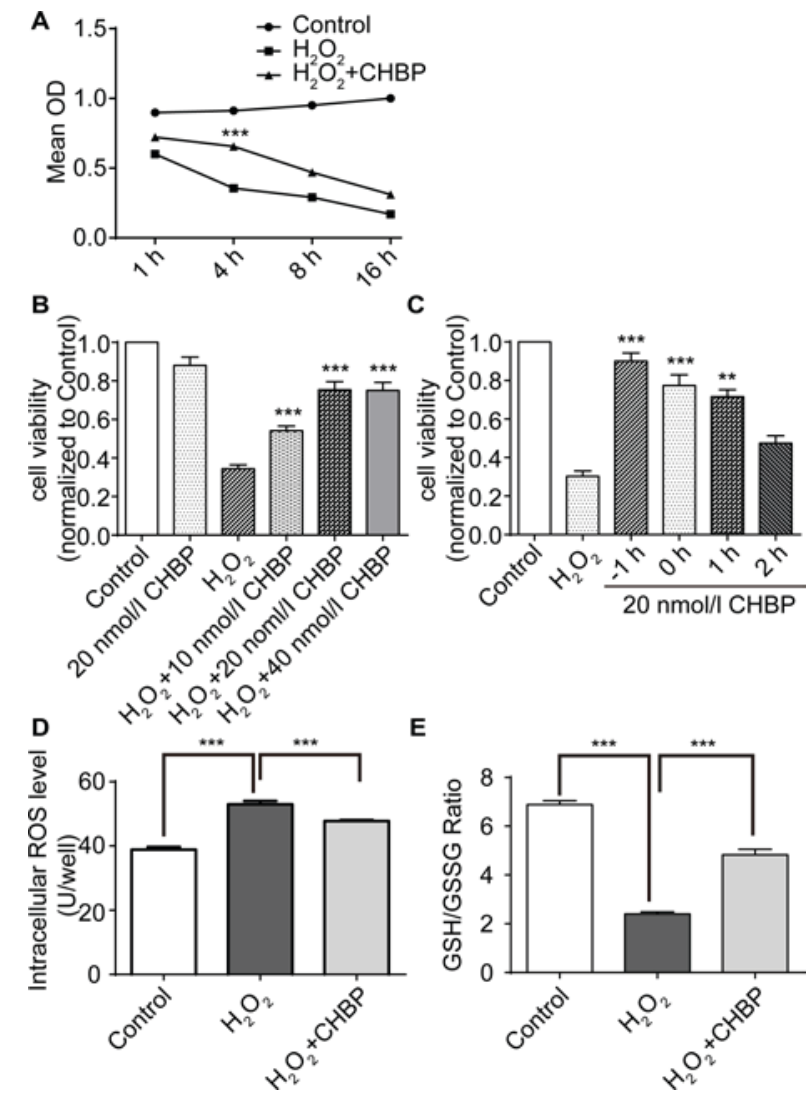

Figure 1. Pretreatment with CHBP enhances HK-2 cell viability by reducing oxidative stress. (A) CHBP pretreatment significantly increased cell viability, particularly after $4 \mathrm{~h} \mathrm{H}_{2} \mathrm{O}_{2}$ exposure. (B) Pretreatment with $\mathrm{CHBP}$ enhanced the viability of $\mathrm{HK}-2$ cells after exposure to $\mathrm{H}_{2} \mathrm{O}_{2}$. (C) CHBP was administrated $1 \mathrm{~h}$ before $\mathrm{H}_{2} \mathrm{O}_{2}$ stimulation or along with $\mathrm{H}_{2} \mathrm{O}_{2}$ stimulation, after 1 , $2 \mathrm{~h}, \mathrm{H}_{2} \mathrm{O}_{2}$ stimulation respectively. The results showed that $\mathrm{CHBP}$ enhanced the viability of $\mathrm{HK}-2$ cells exposed to $\mathrm{H}_{2} \mathrm{O}_{2}$ for $4 \mathrm{~h}$, especially $1 \mathrm{~h}$ pretreatment (D) Effect of CHBP on ROS activity levels in HK-2 cells exposed to $\mathrm{H}_{2} \mathrm{O}_{2}$. (E) Effects of CHBP on the GSH/GSSG ratio in HK-2 cells exposed to $\mathrm{H}_{2} \mathrm{O}_{2}$. Data are expressed as mean \pm standard deviation. ${ }^{* * *} \mathrm{P}<0.01$ and ${ }^{* * * *} \mathrm{P}<0.001$ vs. $\mathrm{H}_{2} \mathrm{O}_{2}$ alone. $\mathrm{n}=6$. OD, optical density; CHBP, cyclic helix B peptide; ROS, reactive oxygen species; GSH/GSSG ratio, glutathione/glutathione disulphide ratio.

whether CHBP reduces oxidative stress induced by $\mathrm{H}_{2} \mathrm{O}_{2}$, ROS activity levels and the GSH/GSSG ratio in HK-2 cells were measured. ROS activity levels in HK-2 cells were enhanced following exposure to $\mathrm{H}_{2} \mathrm{O}_{2}$ compared with the control, and this effect was significantly reduced by CHBP pretreatment 
A

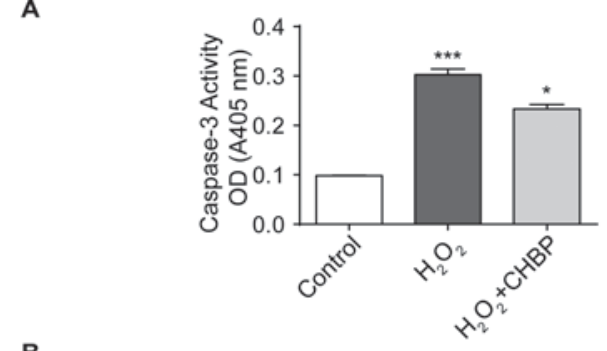

B

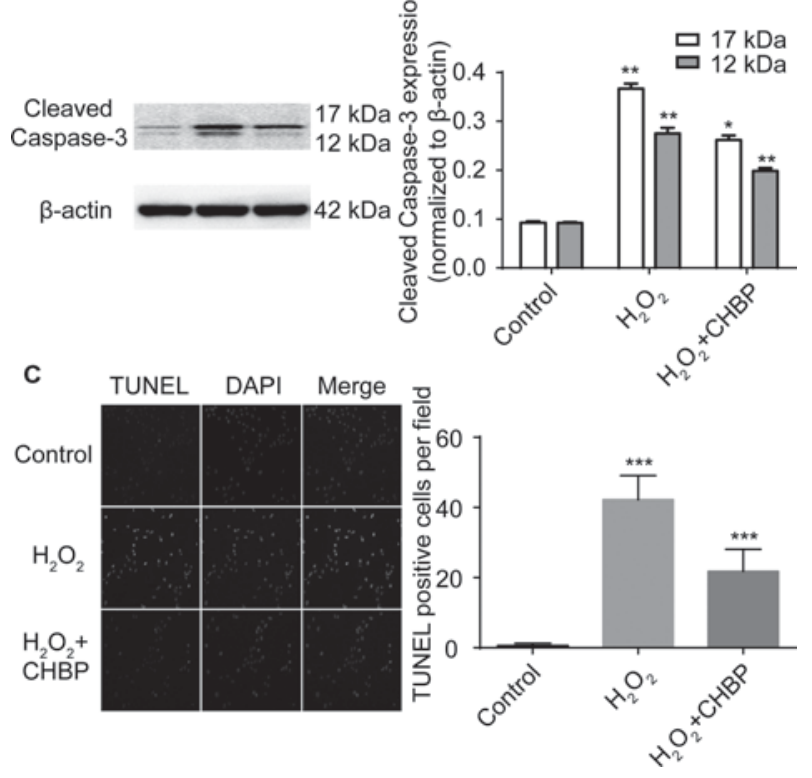

Figure 2. Pretreatment with CHBP inhibits $\mathrm{HK}-2$ apoptosis induced by $\mathrm{H}_{2} \mathrm{O}_{2}$. (A) Pretreatment with CHBP reduced $\mathrm{H}_{2} \mathrm{O}_{2}$-induced caspase-3 activity in HK-2 cells. (B) Pretreatment with CHBP reduced the expression levels of caspase-3 and cleaved caspase-3 in HK-2 cells exposed to $\mathrm{H}_{2} \mathrm{O}_{2}$ Caspase-3 $(17 \mathrm{kDa})$ and cleaved caspase- $3(12 \mathrm{kDa})$ were quantified by normalising to the $\beta$-actin loading control. (C) Pretreatment with CHBP reduced the number of TUNEL positive HK-2 cells following exposure to $\mathrm{H}_{2} \mathrm{O}_{2}$. Original magnification, $\mathrm{x} 200$. Data are expressed as mean \pm standard deviation. ${ }^{*} \mathrm{P}<0.01$, ${ }^{* *} \mathrm{P}<0.01$ and ${ }^{* * * *} \mathrm{P}<0.001$ vs. $\mathrm{H}_{2} \mathrm{O}_{2}$ alone. $\mathrm{n}=6$. OD, optical density; $\mathrm{CHBP}$ cyclic helix B peptide; TUNEL, terminal deoxynucleotidyl transferase-mediated dUTP nick-end label.

(P<0.001; Fig. 1D). In addition, the GSH/GSSG ratio in HK-2 cells was reduced following exposure to $\mathrm{H}_{2} \mathrm{O}_{2}$ compared with the control, and this effect was reversed by pretreatment with CHBP $(\mathrm{P}<0.001$; Fig. 1E). These results suggested that CHBP pretreatment enhances HK-2 cell viability and reduces oxidative stress in HK-2 cells.

CHBP pretreatment inhibits $H K-2$ apoptosis induced by $\mathrm{H}_{2} \mathrm{O}_{2}$. To determine whether CHBP inhibits apoptosis induced by $\mathrm{H}_{2} \mathrm{O}_{2}$, apoptosis in HK-2 cells was measured following treatment. In addition, as activation of caspase- 3 is a marker for apoptosis, caspase-3 activity was measured in HK-2 cells following treatment. The percentage of apoptotic cells was enhanced following $\mathrm{H}_{2} \mathrm{O}_{2}$ treatment alone, whereas pretreatment with $20 \mathrm{nmol} / \mathrm{l} \mathrm{CHBP}$ in the presence of $\mathrm{H}_{2} \mathrm{O}_{2}$ significantly reduced the activity levels of caspase- $3(\mathrm{P}<0.01$; Fig. 2A). Caspase-3 and cleaved caspase- 3 expression levels were enhanced in HK-2 cells following $\mathrm{H}_{2} \mathrm{O}_{2}$ treatment alone, and were significantly reduced by pretreatment with CHBP (Fig. 2B). Additionally, Pretreatment with CHBP significantly reduced the number of TUNEL positive cells in the presence

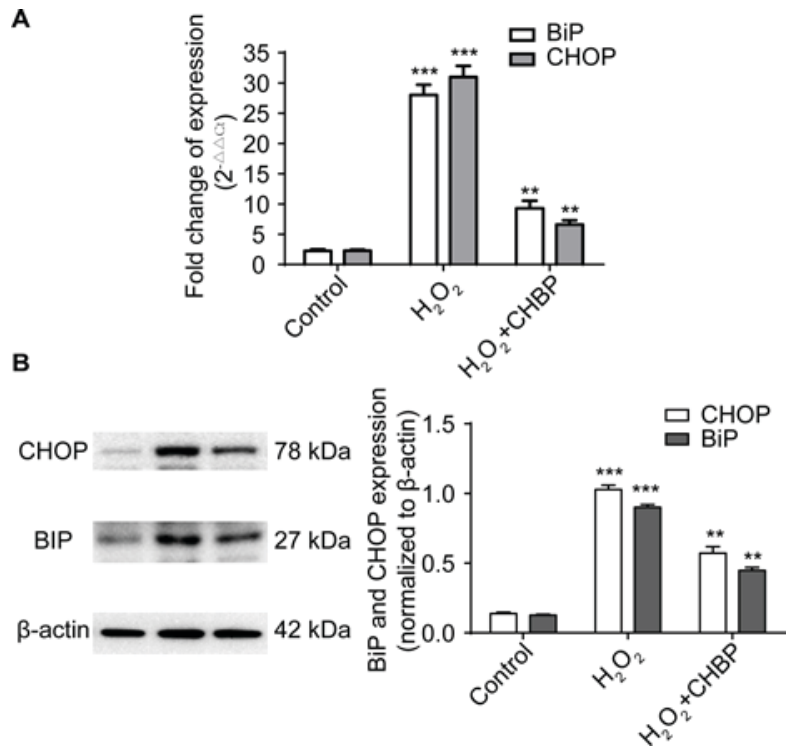

Figure 3. Pretreatment with CHBP reduces ER stress in HK-2 cells exposed to $\mathrm{H}_{2} \mathrm{O}_{2}$. (A) Pretreatment with CHBP reduced the mRNA expression levels of BiP and $\mathrm{CHOP}$, as determined by reverse-transcription-quantitative polymerase chain reaction. (B) Pretreatment with CHBP reduced the protein expression levels of BiP and CHOP, as determined by western blotting and densitometric analysis. Data are expressed as mean \pm standard deviation. ${ }^{* * *} \mathrm{P}<0.01$ vs. $\mathrm{H}_{2} \mathrm{O}_{2}$ alone; ${ }^{* * *} \mathrm{P}<0.001$ vs. control. $\mathrm{n}=6$. $\mathrm{CHBP}$, cyclic helix $\mathrm{B}$ peptide; $\mathrm{BiP}$, binding immunoglobulin protein; $\mathrm{CHOP}, \mathrm{C} / \mathrm{EBP}$ homologous protein.

of $\mathrm{H}_{2} \mathrm{O}_{2}(\mathrm{P}<0.001$; Fig. 2C). These results suggested that CHBP inhibits apoptosis induced by $\mathrm{H}_{2} \mathrm{O}_{2}$.

CHBP pretreatment reduces ER stress in $H K$ - 2 cells exposed to $\mathrm{H}_{2} \mathrm{O}_{2}$. Elevated expression levels of $\mathrm{BiP}$ and $\mathrm{CHOP}$ are features of ER stress (2). To determine whether CHBP decreased ER stress in HK-2 cells, mRNA and protein expression levels of $\mathrm{BiP}$ and CHOP were measured in HK-2 cells following $\mathrm{H}_{2} \mathrm{O}_{2}$ treatment. The mRNA expression levels of the genes encoding $\mathrm{BiP}$ and CHOP were enhanced in cells treated with $\mathrm{H}_{2} \mathrm{O}_{2}$ alone, and these levels were significantly reduced by pretreatment with $\mathrm{CHBP}(\mathrm{P}<0.01$; Fig. 3A). This was supported by the protein expression levels of $\mathrm{BiP}$ and $\mathrm{CHOP}(\mathrm{P}<0.01$; Fig. $3 \mathrm{~B})$. These results suggested that $\mathrm{CHBP}$ pretreatment reduces ER stress in $\mathrm{HK}-2$ cells exposed to $\mathrm{H}_{2} \mathrm{O}_{2}$.

CHBP pretreatment enhances activation of the Nrf2 signalling pathway in $\mathrm{HK}-2$ cells treated with $\mathrm{H}_{2} \mathrm{O}_{2} \mathrm{Nrf2}$ is a transcriptional regulator of antioxidant proteins, including HO-1 (12). To determine whether CHBP activates the Nrf2 signalling pathway in HK-2 cells treated with $\mathrm{H}_{2} \mathrm{O}_{2}$, expression levels of intranuclear and extranuclear Nrf2 and HO-1 were measured following pretreatment with CHBP. Nrf2 expression levels were enhanced in the nuclei of HK-2 cells after $\mathrm{H}_{2} \mathrm{O}_{2}$ treatment alone, $(\mathrm{P}<0.001$; Fig. 4A), and were further enhanced by pretreatment with CHBP $(\mathrm{P}<0.001$; Fig. 4A). Similar results were observed in the extranuclear portion of HK-2 cells $(\mathrm{P}<0.001$; Fig. 4B) via western blotting. In addition, these results were supported by the immunocytochemistry data for the Nrf2 protein (Fig. 4C). These results suggested that CHBP pretreatment enhances activation of the Nrf2 signalling pathway in HK-2 cells exposed to $\mathrm{H}_{2} \mathrm{O}_{2}$. 
A

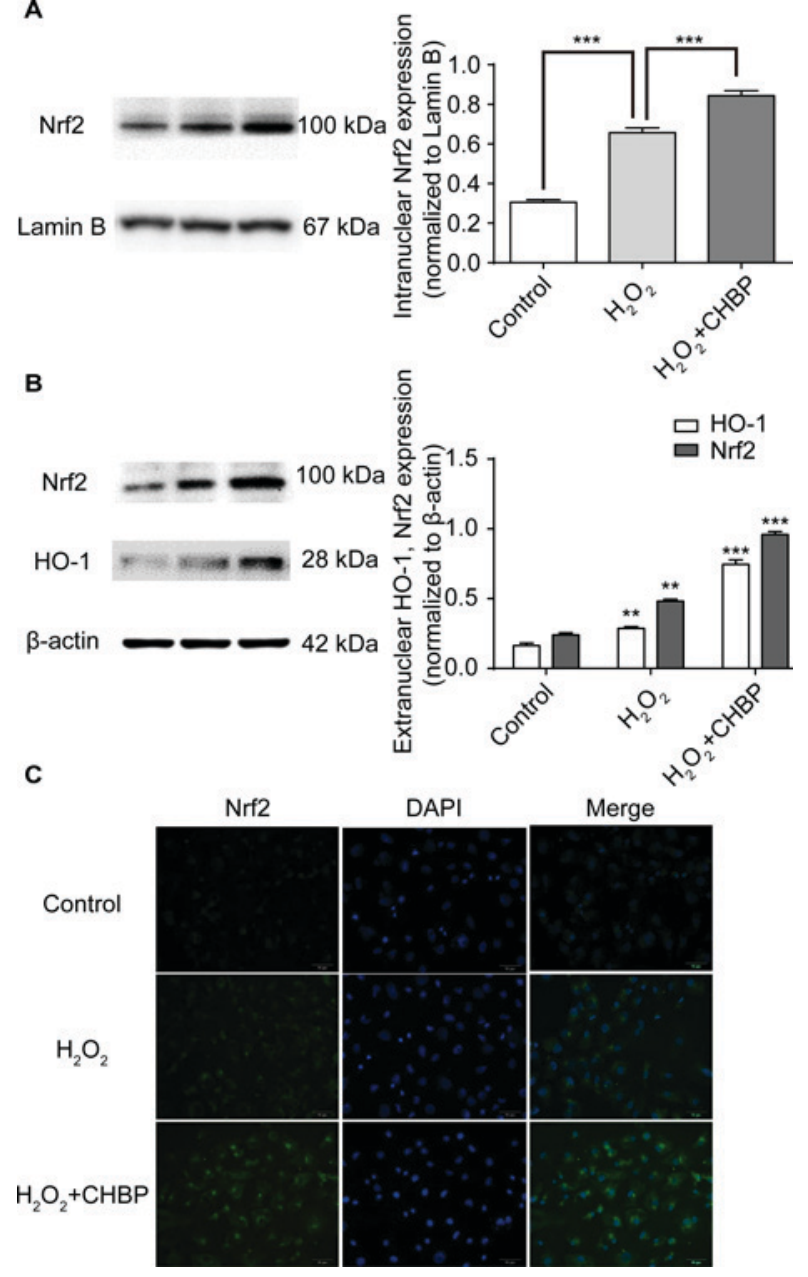

Figure 4. Pretreatment with CHBP enhances activation of the Nrf2 signalling pathway in HK-2 cells exposed to $\mathrm{H}_{2} \mathrm{O}_{2}$. (A) Pretreatment with CHBP enhanced intranuclear Nrf2 expression levels in HK-2 cells treated with $\mathrm{H}_{2} \mathrm{O}_{2}$, as determined by western blotting and densitometric analysis. (B) Pretreatment with CHBP enhanced extranuclear Nrf2 and HO-1 expression levels in HK-2 cells treated with $\mathrm{H}_{2} \mathrm{O}_{2}$, as determined by western blotting and densitometric analysis. (C) Pretreatment with CHBP enhanced Nrf2 expression levels in HK-2 cells exposed to $\mathrm{H}_{2} \mathrm{O}_{2}$, as demonstrated by immunocytochemistry. Original magnification, $x 200$. Data are expressed as mean \pm standard deviation. ${ }^{* * * *} \mathrm{P}<0.001$ vs. control; ${ }^{* * * *} \mathrm{P}<0.001$ vs. $\mathrm{H}_{2} \mathrm{O}_{2}$ alone. $\mathrm{n}=6$. CHBP, cyclic helix B peptide; Nrf2, NF-E2-related factor 2; HO-1, heme oxygenase-1.

CHBP pretreatment enhances autophagy in $H K-2$ cells treated with $\mathrm{H}_{2} \mathrm{O}_{2}$. Our previous in vivo study demonstrated that the renoprotective effect of CHBP against IRI is mediated by induction of autophagy via inhibition of mTOR complex (C) 1 and activation of mTORC2 (9). As oxidative stress may crosstalk with autophagic machinery, the present study determined whether the renoprotective function of CHBP is mediated by autophagy in HK-2 cells after $\mathrm{H}_{2} \mathrm{O}_{2}$ treatment. Results demonstrated that beclin-1 and LC3 A/B-II/I expression levels were significantly enhanced, and the expression of p62 following CHBP pretreatment was reduced much more compared with $\mathrm{H}_{2} \mathrm{O}_{2}$ alone (Fig. 5A). However, the expression of p-mTOR Ser2481 following CHBP pretreatment was increased more than that of $\mathrm{H}_{2} \mathrm{O}_{2}$ alone. By contrast, p-mTOR Ser2448 levels were enhanced in $\mathrm{HK}-2$ cells after $\mathrm{H}_{2} \mathrm{O}_{2}$ stimulation, and were significantly reduced by CHBP pretreatment (Fig. 5B). These results suggested that CHBP pretreatment enhances autophagy in HK-2 cells under oxidative stress.

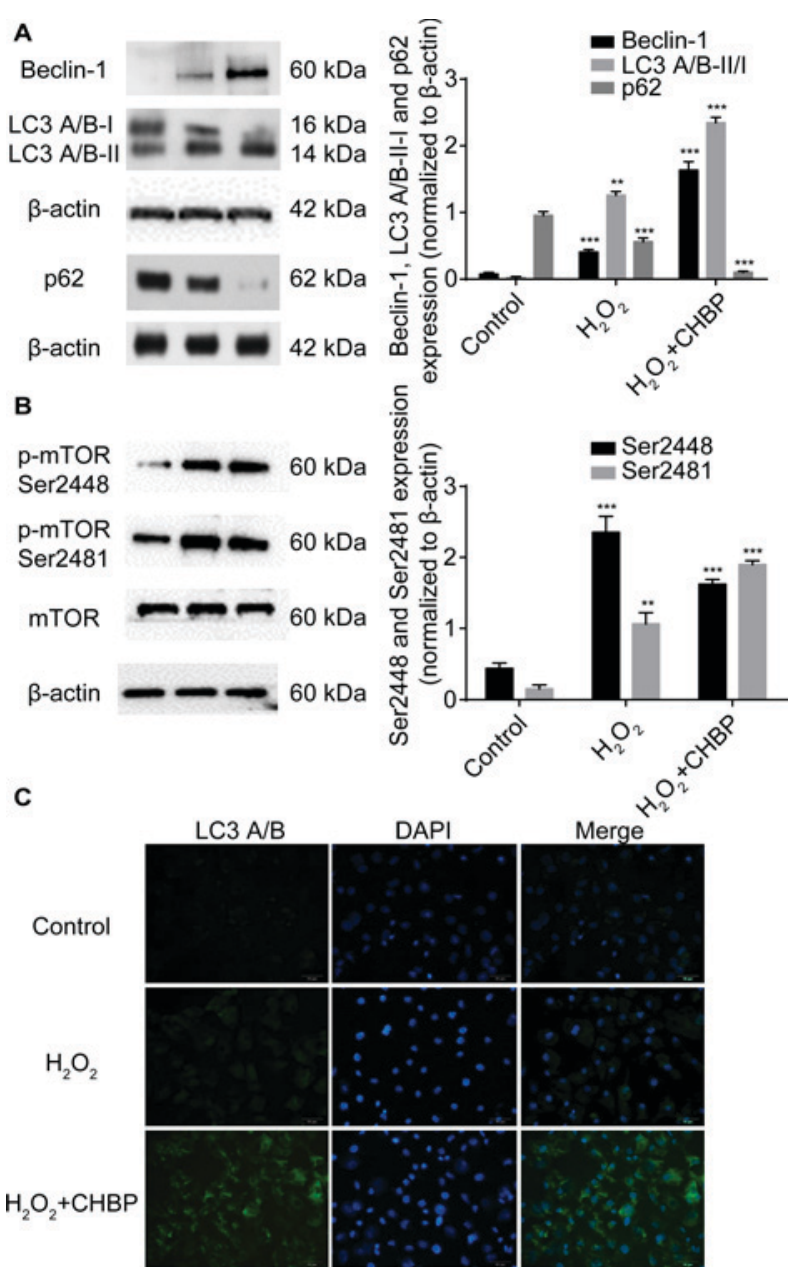

Figure 5. Pretreatment with $\mathrm{CHBP}$ enhances autophagy in HK-2 cells exposed to $\mathrm{H}_{2} \mathrm{O}_{2}$. (A) Pretreatment with CHBP enhanced the expression levels of Beclin-1 and LC3 A/B-II/I in HK-2 cells treated with $\mathrm{H}_{2} \mathrm{O}_{2}$; however, p62 expression level were reduced, as demonstrated by western blotting. (B) Pretreatment with CHBP enhanced p-mTOR Ser2481 expression levels in $\mathrm{HK}-2$ cells treated with $\mathrm{H}_{2} \mathrm{O}_{2}$, and reduced expression levels of p-mTOR Ser2448, as demonstrated by western blotting. (C) Pretreatment with CHBP enhanced LC3 A/B-II/I expression levels in HK-2 cells treated with $\mathrm{H}_{2} \mathrm{O}_{2}$, as demonstrated by immunocytochemistry and immunofluorescence microscopy. Data are expressed as mean \pm standard deviation. ${ }^{* * *} \mathrm{P}<0.001$ and ${ }^{* *} \mathrm{P}<0.01$ vs. $\mathrm{H}_{2} \mathrm{O}_{2}$ alone. $\mathrm{n}=6$. CHBP, cyclic helix $\mathrm{B}$ peptide; LC3 A/B-II/I, light chain 3 A/B-II/I; p-mTOR, phosphorylated-mechanistic target of rapamycin.

\section{Discussion}

In the present study, to further evaluate the protective role of CHBP in renal IRI, the effect and underlying mechanism of CHBP on the HK-2 human renal proximal tubular cell line was investigated under oxidative stress induced by $\mathrm{H}_{2} \mathrm{O}_{2}$. Under $\mathrm{H}_{2} \mathrm{O}_{2}$-induced oxidative stress, CHBP pretreatment enhanced HK-2 cell viability, the GSH/GSSG ratio, activation of the Nrf2 signalling pathway and proteins involved in autophagy. However, CHBP pretreatment reduced the activity levels of ROS, apoptosis and ER stress. This suggested that CHBP protects cells from renal IRI, possibly via the inhibition of ER stress and pro-apoptotic pathways, and via activation of the Nrf2 signalling pathway.

In the present study, HK-2 cells were treated with $\mathrm{H}_{2} \mathrm{O}_{2}$ in an in vitro model to mimic oxidative stress-induced injury 
during IRI, and to evaluate the protective effect of CHBP. IRI is characterized by TEC injury. It is present in numerous diseases and following certain treatments, including shock, renal transplantation and cardiac surgery (1). TECs contribute to key renal function (13). It has been demonstrated that following renal transplantation, apoptosis of TEC during IRI results in loss of kidney function and delays graft function, which greatly affects clinical outcome (13). Therefore, HK-2 cells are a useful in assessing the effect of CHBP on IRI in vitro.

In the present study, ROS activity levels, the GSH/GSSG ratio and Nrf2 signalling proteins were measured to investigate the underlying mechanism of the protective effect of CHBP. The GSH/GSSG ratio is an indicator of prevention of cell damage caused by oxygen species, including free radicles and peroxides. A high GSH/GSSG ratio indicates less oxidative damage (14). Nrf2 mediates the cellular antioxidant response. This is a critical cellular defence in the adaptive UPR response (11). ER stress activates extracellular regulated kinases via phosphorylation, including protein kinase RNA-like endoplasmic reticulum kinase and the IRE1 $\alpha$-JNK-Nrf2 axis, which are initiators of Nrf2 signalling (6). Nrf2 serves a key role in renal IRI. A previous study has demonstrated that Nrf2 knockout mice are more susceptible to renal IRI (15). The gene that encodes HO-1 is a target of Nrf2 (16). Our results suggest that CHBP protects $\mathrm{HK}-2$ cells from $\mathrm{H}_{2} \mathrm{O}_{2}$-induced injury by reducing oxidative stress and activating the antioxidant $\mathrm{Nrf} 2$ signalling pathway. The present in vitro study supports our previous study using a murine model (9).

In the present study, caspase-3, CHOP and BiP expression levels were measured to investigate the underlying mechanism of the protective effect of CHBP. Caspases serve a key role in the initiation and effector phases of apoptosis. Caspase-3 is a downstream effector of the caspase activation cascade, and directly mediates apoptosis when activated by various upstream signals (17). Elevated caspase activity is associated with enhanced apoptosis. The ER is an important organelle in eukaryotes. ER stress contributes to apoptosis of TECs in renal IRI. Moderate ER stress is associated with the adaptive response of the UPR, leading to re-equilibration of the ER (18). During IRI, intensive ER stress occurs and the UPR shifts into the apoptotic phase. CHOP and BiP are involved in this process. $\mathrm{BiP}$ is an important chaperone in the ER lumen, and mediates polypeptide folding and the structural maturation of nascent glycoproteins (19). Accumulation of CHOP initiates intensive ER stress (2). The results of the present study suggested that CHBP protects HK-2 cells from $\mathrm{H}_{2} \mathrm{O}_{2}$-induced injury by inhibiting ER stress and pro-apoptotic pathways, and is consistent with our previous study using a murine model (9).

Our previous in vivo study demonstrated that the renoprotective effect of CHBP against IRI is mediated by induction of autophagy via inhibition of mTORC1 and activation of mTORC2 (9). As oxidative stress may crosstalk with autophagic machinery, it was determined whether the renoprotective function of CHBP is mediated by autophagy in vitro under conditions of oxidative stress. Consistently, expression levels of beclin-1 and LC3 A/B-II/I in HK-2 cells exposed to $\mathrm{H}_{2} \mathrm{O}_{2}$ were enhanced following CHBP pretreatment. p62, is additionally known as SQSTM1 or sequestome
1 , and interacts with polyubiquitinated protein aggregates via a ubiquitin-binding domain, and with LC3 via its LC3-binding domain, therefore targeting these aggregates for degradation by the autolysosome (20). In the present study, pretreatment with CHBP further reduced the expression levels of p62 in HK-2 cells treated with $\mathrm{H}_{2} \mathrm{O}_{2}$. In addition, pretreatment with CHBP reduced p-mTOR Ser2448 and enhanced p-mTOR Ser2481 expression levels. These results support the theory that CHBP induces autophagy to protect against oxidative stress.

CHBP is derived from HBSP, which has a very short plasma half-life, and therefore requires frequent administration at high doses to achieve tissue-protective effects (21). However, our previous study demonstrated that CHBP is metabolically stable and protects mice from renal IRI via inhibition of apoptosis and inflammation (9).

In conclusion, the present study revealed that CHBP protects $\mathrm{HK}-2$ cells from $\mathrm{H}_{2} \mathrm{O}_{2}$-induced injury by inhibiting ER stress and pro-apoptotic pathways, and via activation of the Nrf2 signalling pathway and autophagy. Therefore, CHBP may be a promising pharmacological agent for the prevention of renal IRI.

\section{Acknowledgements}

This study was supported by grants from the National Nature Science Foundation of China (grant nos. 81270833, 81300621 and 81500568), National Health and Family Planning Commission Foundation of Shanghai (grant no. 2014JQ008A).

\section{References}

1. Snoeijs MG, Vink H, Voesten N, Christiaans MH, Daemen JW, Peppelenbosch AG, Tordoir JH, Peutz-Kootstra CJ, Buurman WA, Schurink GW and van Heurn LW: Acute ischemic injury to the renal microvasculature in human kidney transplantation. Am J Physiol Renal Physiol 299: F1134-F1140, 2010.

2. Dong B, Zhou H, Han C, Yao J, Xu L, Zhang M, Fu Y and Xia Q: Ischemia/reperfusion-induced CHOP expression promotes apoptosis and impairs renal function recovery: The role of acidosis and GPR4. PLoS One 9: e110944, 2014.

3. Yang JR, Yao FH, Zhang JG, Ji ZY, Li KL, Zhan J, Tong YN, Lin LR and He YN: Ischemia-reperfusion induces renal tubule pyroptosis via the CHOP-caspase-11 pathway. Am J Physiol Renal Physiol 306: F75-F84, 2014.

4. Liu J, Ren F, Cheng Q, Bai L, Shen X, Gao F, Busuttil RW, Kupiec-Weglinski JW and Zhai Y: Endoplasmic reticulum stress modulates liver inflammatory immune response in the pathogenesis of liver ischemia and reperfusion injury. Transplantation 94: 211-217, 2012.

5. Pierre N, Barbe C, Gilson H, Deldicque L, Raymackers JM and Francaux M: Activation of ER stress by hydrogen peroxide in C2C12 myotubes. Biochem Biophys Res Commun 450: 459-463, 2014.

6. Digaleh H, Kiaei M and Khodagholi F: Nrf2 and Nrf1 signaling and ER stress crosstalk: Implication for proteasomal degradation and autophagy. Cell Mol Life Sci 70: 4681-4694, 2013.

7. Ueba H, Brines M, Yamin M, Umemoto T, Ako J, Momomura S, Cerami A and Kawakami M: Cardioprotection by a nonerythropoietic, tissue-protective peptide mimicking the 3D structure of erythropoietin. Proc Natl Acad Sci USA 107: 14357-14362, 2010.

8. Brines M, Patel NS, Villa P, Brines C, Mennini T, De Paola M, Erbayraktar Z, Erbayraktar S, Sepodes B, Thiemermann C, et al: Nonerythropoietic, tissue-protective peptides derived from the tertiary structure of erythropoietin. Proc Natl Acad Sci USA 105: 10925-10930, 2008.

9. Yang C, Xu Z, Zhao Z, Li L, Zhao T, Peng D, Xu M, Rong R, Long YQ and Zhu T: A novel proteolysis-resistant cyclic helix B peptide ameliorates kidney ischemia reperfusion injury. Biochim Biophys Acta 1842: 2306-2317, 2014. 
10. Lin M, Li L, Li L, Pokhrel G, Qi G, Rong R and Zhu T: The protective effect of baicalin against renal ischemia-reperfusion injury through inhibition of inflammation and apoptosis. BMC Complement Altern Med 14: 19, 2014.

11. Livak KJ and Schmittgen TD: Analysis of relative gene expression data using real-time quantitative PCR and the 2(-Delta Delta C(T)) method. Methods 25: 402-408, 2001.

12. González-Guerrero C, Ocaña-Salceda C, Berzal S, Carrasco S, Fernández-Fernández B, Cannata-Ortiz P, Egido J, Ortiz A and Ramos AM: Calcineurin inhibitors recruit protein kinases JAK 2 and JNK, TLR signaling and the UPR to activate NF-kappaB-mediated inflammatory responses in kidney tubular cells. Toxicol Appl Pharmacol 272: 825-841, 2013.

13. Gobé G, Willgoss D, Hogg N, Schoch E and Endre Z: Cell survival or death in renal tubular epithelium after ischemia-reperfusion injury. Kidney Int 56: 1299-1304, 1999.

14. Manikonda PK, Rajendra P, Devendranath D, Gunasekaran B, Channakeshava, Aradhya SR, Sashidhar RB and Subramanyam C: Extremely low frequency magnetic fields induce oxidative stress in rat brain. Gen Physiol Biophys 33: 81-90, 2014.

15. Ke B, Shen XD, Zhang Y, Ji H, Gao F, Yue S, Kamo N, Zhai Y, Yamamoto M, Busuttil RW and Kupiec-Weglinski JW: KEAP1-NRF2 complex in ischemia-induced hepatocellular damage of mouse liver transplants. J Hepatol 59: 1200-1207, 2013.
16. Kang JS, Han MH, Kim GY, Kim CM, Kim BW, Hwang HJ and Hyun Y: Nrf2-mediated HO-1 induction contributes to antioxidant capacity of a Schisandrae Fructus ethanol extract in C2C12 myoblasts. Nutrients 6: 5667-5678, 2014

17. Seo HS, Ku JM, Choi HS, Woo JK, Jang BH, Shin YC and Ko SG: Induction of caspase-dependent apoptosis by apigenin by inhibiting STAT3 signaling in HER2-overexpressing MDA-MB-453 breast cancer cells. Anticancer Res 34: 2869-2882, 2014.

18. Lindenmeyer MT, Rastaldi MP, Ikehata M, Neusser MA, Kretzler M, Cohen CD and Schlöndorff D: Proteinuria and hyperglycemia induce endoplasmic reticulum stress. J Am Soc Nephrol 19: 2225-2236, 2008.

19. Shimazawa M, Tanaka H, Ito Y, Morimoto N, Tsuruma K, Kadokura M, Tamura S, Inoue T, Yamada M, Takahashi H, et al: An inducer of VGF protects cells against ER stress-induced cell death and prolongs survival in the mutant SOD1 animal models of familial ALS. PLoS One 5: e15307, 2010.

20. Pankiv S, Clausen TH, Lamark T, Brech A, Bruun JA, Outzen H, Øvervatn A, Bjørkøy G and Johansen T: p62/SQSTM1 binds directly to Atg8/1C3 to facilitate degradation of ubiquitinated protein aggregates by autophagy. J Biol Chem 282: 24131-24145, 2007.

21. McVicar CM, Hamilton R, Colhoun LM, Gardiner TA, Brines M, Cerami A and Stitt AW: Intervention with an erythropoietin-derived peptide protects against neuroglial and vascular degeneration during diabetic retinopathy. Diabetes 60: 2995-3005, 2011 